\title{
The formation mechanisms of growth twins in polycrystalline Al with high stacking fault energy
}

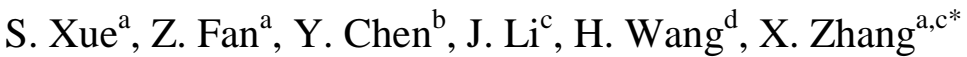 \\ ${ }^{a}$ Department of Mechanical Engineering, Texas A\&M University, College Station, TX 77843 \\ ${ }^{b}$ Materials Science and Technology Division, Los Alamos National Laboratory, Los Alamos, NM \\ 87545 \\ ${ }^{c}$ Department of Materials Science and Engineering, Texas A\&M University, College Station, TX \\ 77843 \\ ${ }^{d}$ Department of Electrical Engineering, Texas A\&M University, College Station, TX 77843 \\ *Corresponding author: X. Zhang, zhangx @tamu.edu
}

\begin{abstract}
:
Growth twins are scarcely observed in metals with high stacking fault energy, such as pure Al. In this study, however, we report the observation of growth twins in sputtered polycrystalline Al films on amorphous substrates and a majority of these growth twins are inclined to the growth direction (inclined twins). Although the fraction of twinned grains is low in general, it increases monotonically with increasing film thickness, reaches a maximum at the film thickness of $80 \mathrm{~nm}$, and decreases gradually thereafter in the thicker films. The nucleation mechanism for the inclined twins is compared with that of the parallel growth twins in Al. Different twin formation mechanisms are discussed. This study provides an alternative perspective to evaluate the formation of growth twins in metals with high stacking fault energy.
\end{abstract}

Key words: nanotwinned Al; growth twin; defect nucleation kinetics

(C) 2015. This manuscript version is made available under the Elsevier user license 1 http://www.elsevier.com/open-access/userlicense/1.0/ 


\section{Introduction}

Nanotwinned (nt) metals have been intensely studied and show various unique properties. $\mathrm{Cu}$ with nanotwins have excellent electrical conductivity $[1,2]$ while maintaining high mechanical strength. Nt metals, such as $\mathrm{Cu}$ and $\mathrm{Ag}$ [3-6], also show better thermal stability than monolithic nanocrystalline (nc) metals [7-9]. The mechanical properties of nt metals have also been extensively studied [2, 3, 9-19]. Nanotwins enhance the mechanical properties of metals via various mechanisms, some of which are briefly summarized as follows. First, molecular dynamics (MD) simulations have shown that glide dislocations can be blocked by the $\sum 3(111)$ coherent twin boundary (CTB) $[12,14,20,21]$ and $\Sigma 3(112)$ incoherent twin boundary [22-24]. A very high stress is necessary to transmit dislocations across TBs [25, 26]. In situ nanoindentation studies of nt $\mathrm{Cu}$ confirm significant interactions between dislocations and CTBs/ITBs [27, 28]. Second, high density dislocations can accumulate at the CTBs and thus enhance work hardening capability and ductility comparing with nc metals $[10,29,30]$. Third, TBs are mobile manifested as detwinning in $\mathrm{nt} \mathrm{Cu}$ as have been observed experimentally by ex situ shear deformation $[16$, 31-33] or in situ nanoindentation and validated by $\mathrm{MD}$ simulations [15, 27]. The stress for detwinning of fine nanotwins can be exceptionally low, $\sim 100 \mathrm{MPa}$, much lower than the yield strength of nt $\mathrm{Cu}[27]$.

Prior studies on twins focus primarily on metals with low stacking fault energy (SFE), such as $\mathrm{Cu}, \mathrm{Ag}, \mathrm{GaP}$ and 330 stainless steels [9-11, 16, 34-43]. Because of the appealing mechanical properties induced by TBs, there are increasing interest in synthesis of twinned lightweight metals, such as Al. Although twins can be introduced into fcc metals by annealing (annealing twins), deformation (deformation twins) and growth (growth twins), the twinnability of fcc metals remains largely controlled by their SFE [34, 35, 44-48]. Consequently it is much 
more difficult to introduce twins in high SFE metals than those with low SFE. The prediction of deformation twin in $\mathrm{nc}$ Al by molecular dynamics simulation [46, 49] leads to a series of successful discovery that shows twins can indeed be introduced via nanoindentation [50], tensile test [10] or cryomilling [51] in nc Al. These evidence give us a hint that although the Al has an inherently high SFE barrier to form twins, other factors, such as grain size $[52,53]$, strain rate $[54,55]$ and high stress concentration [56], may trigger the formation of twins.

Recently high-density growth twins and stacking faults have been fabricated in Al by introducing nt Ag buffer layers [57-59] by the magnetron sputtering technique. The Al film grown epitaxially on $\mathrm{Ag}$ replicates the microstructures including twins from the $\mathrm{Ag}$ seed layer because $\mathrm{Ag}$ and $\mathrm{Al}$ has identical lattice parameter and crystal structure. A systematic study on various metallic multilayers leads to two criteria for the introduction of growth twins into high SFE metals [60]. The first criterion emphasize the need for a low SFE buffer layer that can readily form high-density twinned seeds; and the second criterion highlights the significance of global coherency between coherent similar interface (between constituents with identical planar indices) or local coherency between coherent dissimilar interfaces (between constituents with different planar indices) that allow twins to propagate across layer interfaces. Although highdensity growth twins have been introduced into Al with the assistance of the buffer layers, whether growth twins can be synthesized in Al without low SFE metal buffer layers remains an unanswered question.

In this article, we present a simple method to introduce twins into polycrystalline Al films by DC magnetron sputtering without low SFE metallic seed layer. By controlling the film thickness, the fraction of twinned grains in Al can increase to nearly $10 \%$. We also investigated 
the inverse film thickness effect on the formation of twins in thicker Al films. The twin formation mechanisms, including nucleation and growth of twins, are discussed.

\section{Experimental}

Polycrystalline $\mathrm{Al}$ films were deposited at room temperature by DC magnetron sputtering using $99.99 \%$ purity Al target onto Si substrates and sample grids supported with carbon film for transmission electron microscopy (TEM) studies. The aluminum films of different thickness (20$180 \mathrm{~nm}$ ) were deposited by controlling deposition time under the same deposition rate, $0.7 \mathrm{~nm} / \mathrm{s}$. The base pressure of the vacuum system prior to deposition was $\sim 8 \times 10^{-8}$ torr or better and Ar gas pressure was $\sim 2.5 \times 10^{-3}$ torr during magnetron sputtering. TEM studies were performed on an FEI Tecnai F20 ST electron microscope operated at $200 \mathrm{kV}$ and equipped with a Fischione ultra-high resolution high-angle annular dark field (HAADF) detector. For the statistic studies on the distributions of grain size and twin thickness, $\sim 500$ grains were measured for each specimen with different film thicknesses, and over 1,200 grains were counted for each film to calculate the fraction of twinned grains at different locations in order to establish statistical significance.

\section{Results}

Plan-view TEM micrographs are shown in Fig. 1 for polycrystalline Al films with different film thickness (h) deposited on TEM grids. In the $20 \mathrm{~nm}$ thick Al films in Fig. 1a, growth twins were observed as labeled selectively by arrows. The average grain size $\left(D_{\text {ave }}\right)$ is 30 nm. The inserted selected area diffraction (SAD) pattern (collected with a large aperture to include numerous grains) shows numerous continuous rings, such as (111), (220) and (200) 
diffractions, arising from nc grains. When the film thickness (h) increases to $100 \mathrm{~nm}$, the SAD pattern in Fig. 1e shows film texture barely changes. Meanwhile the grain size of the Al film increases to over $100 \mathrm{~nm}$ when $\mathrm{h}=140 \mathrm{~nm}$. Fig.2a shows a CTB multi-junction containing two 2-fold twins. The white dash box b in Fig. 2a is magnified in the high resolution TEM (HRTEM) micrograph in Fig. 2b. Each of the 2-fold twins contains 2 CTBs (CTB1 and 2). The two nodes are connected by a highly distorted boundary that is nearly parallel to the $\{111\}$ plane. The fast Fourier transform (FFT) of Fig. 2b shows the relationship between the two sets of TBs in Fig. 2c.

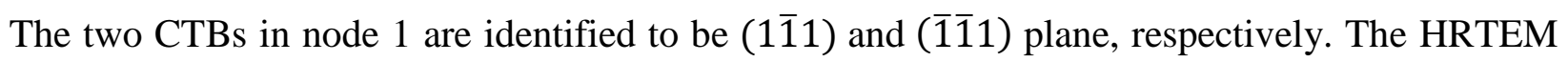
micrograph of the box d (in Fig. 2a) shows stacking faults (SF) adjacent to the TB (Fig. 2d).

Statistical studies in Fig. 3a show that the average grain size $\left(D_{\text {ave }}\right)$ increases monotonically from 30 to $\sim 110 \mathrm{~nm}$ with film thickness when $\mathrm{h} \leq 80 \mathrm{~nm}$; and it then approaches a plateau, $\sim 140 \mathrm{~nm}$, in thicker films. In parallel with the increase of film thickness, the average twin spacing ( $\mathrm{T}_{\text {ave }}$ ) also increases, from 12 to $44 \mathrm{~nm}$, when $\mathrm{h} \leq 80 \mathrm{~nm}$; and approaches $57 \mathrm{~nm}$ when $\mathrm{h}=180 \mathrm{~nm}$. The ratio of $\mathrm{T}_{\text {ave }} / \mathrm{D}_{\text {ave }}$ is $\sim 40 \%$ with little dependence on film thickness. Fig. 4 summarizes the evolution of $T_{a v e}$ and $D_{\text {ave }}$ with film thickness. Meanwhile the fraction of twinned grains rises monotonically and reaches a maximum of $9.5 \%$ when $\mathrm{h}=80 \mathrm{~nm}$, which is twice as much as the fraction of twinned grains in the $20 \mathrm{~nm}$-thick films. The fraction of twinned grains then decreases thereafter in the thicker films.

\section{Discussion}

The formation mechanisms of growth twins in Al 
Our previous studies show that the epitaxial growth of Al on highly twinned Ag seed layer prompts the extension of nanotwins (nucleated in $\mathrm{Ag}$ ) into $\mathrm{Al}$ films [58]. In this study, however, the twinned polycrystalline Al thin films were synthesized by DC magnetron sputtering without the assistance of any Ag seed layers. From the thermodynamics point of view, it has been shown that an increase in deposition rate will prompt the formation of growth twins in metals [35]. Such a prediction has been validated in $\mathrm{Cu}$ experimentally [61]. Bufford et al [4] used the same twin nucleation model [35] to illustrate that twins are rarely observed in Al films even at a very high deposition rate because of its high SFE. However, the previous thermodynamic model, which was constructed based on the assumption that the TB is parallel to the substrate (referred to as a parallel twin hereafter), cannot predicate the emergence of growth twins (most of which are inclined twins) in the current polycrystalline Al films. Parallel twins have been frequently observed in sputtered nt metals, such as $\mathrm{Cu}, \mathrm{Ag}$ and 330 stainless steels $[1,4,26]$. These sputtered twinned films typically have a strong $\{111\}$ texture. In comparison, when the $\mathrm{nt} \mathrm{Ag}$ films have [110] texture, inclined twins have been observed [4]. In the current study, nanotwins in polycrystalline $\mathrm{Al}$ were observed in plan-view TEM specimens, implying that a majority of these are inclined twins and TBs intersect the film surfaces.

Cross-section TEM (XTEM) micrographs in Fig. 5 (for the Al films grown on $\mathrm{Si}$ substrate) show several examples where inclined twins formed. In the first case as shown in Fig. 5a, the inclined twins (manifested by CTB) nucleated from Si-film interface and extended into the film (to a height of $\sim 220 \mathrm{~nm}$ ) until it is terminated by the columnar grain boundary. Note that this film is thicker than most of the films that were grown on TEM washer. The SAD pattern of the same film in Fig.5b shows the formation of a $\{111\}$ CTB. Based on the observation of these 
inclined twins, we will discuss the revised thermodynamics model to describe the formation of the inclined twins in Al.

\section{A revised thermodynamics model for the formation of inclined twins in metals with high SFE}

We will compare the nucleation mechanisms of a perfect nucleus, a nucleus with a parallel twin and a nucleus with an inclined CTB as shown schematically in Fig. 6. The perfect nucleus in Fig. 6a has the $\{111\}$ texture. The parallel twin nucleus in Fig. $6 \mathrm{~b}$ has the same texture and the CTB is normal to the growth direction. For the inclined twin nucleus with $\{100\}$ texture (the mechanism is similar for $\{110\}$ texture $)$, the $\{111\}$ CTB formed a finite angle $\left(\neq 90^{\circ}\right)$ with respect to the growth direction. As shown in Fig. 6c, the CTB separates the twin nucleus into a right and left section. The right portion of the nucleus has essentially a coherent interface with the matrix, whereas the left portion forms an ITB with the matrix. The angle $\theta$ between the CTB and the matrix/nucleus interface plane is the angle between (111) and (100) plane in this scenario. Based on the twin nucleation model developed by Zhang et al [35], during physical vapor deposition, the total Gibbs free energy of a disc-shaped 'perfect' nucleus $\left(\Delta \mathrm{G}_{1}\right)$, the parallel twin nucleus $\left(\Delta \mathrm{G}_{2}\right)$ and the inclined twin nucleus $\left(\Delta \mathrm{G}_{3}\right)$ are given as:

$$
\begin{aligned}
& \Delta \mathrm{G}_{1}=2 \pi r h \gamma-\pi r^{2} h \Delta G_{V} \\
& \Delta \mathrm{G}_{2}=2 \pi r h \gamma-\pi r^{2} h \Delta G_{V}+\pi r^{2} \gamma_{C T B} \\
& \Delta \mathrm{G}_{3}=2 \pi r h \gamma-\pi r^{2} h \Delta G_{V}+l(h / \sin \theta) \gamma_{C T B}+A_{I T B} \gamma_{I T B}
\end{aligned}
$$


where the $\mathrm{r}$ and $\mathrm{h}$ are the respective nucleus radius and height. $\gamma$ is the surface energy and $\Delta G_{V}$ is the bulk free energy difference between solid and vapor per unit volume driving the nucleation. $\gamma_{C T B}$ and $\gamma_{I T B}$ are the respective energy of CTB and ITB. $A_{I T B}$ is the area of ITB at the filmsubstrate interface. The CTB in the inclined twin nucleus has a truncated ellipse shape, which can be approximately to be a rectangle. The area of CTB can thus can be calculate as $l h$, where $l$, the length of the rectangle, is the intersection between the CTB and matrix as shown in Fig. 6c, and the other edge of the rectangle can be estimated as $\mathrm{h} / \sin \theta$. If the area of the ITB $A_{\text {ITB }}=$ $f \pi r^{2}$, where $f$ is the fraction of the ITB area with respect to the area of the nucleus/matrix interface, then $l=2 \lambda r$, where $\lambda$ is determined by $f$.

Then following the prior practice [35], the critical nucleation radius for different type of nucleus can be calculated as:

$$
\begin{aligned}
& r_{\text {perfect }}^{*}=\frac{\gamma}{\Delta G_{V}}=\frac{\gamma}{\left(\frac{k T}{\Omega} \ln \left[\frac{J \sqrt{2 \pi m k T}}{P_{s}}\right]\right)}(4) \\
& r_{\text {parallel }}^{*}=\frac{\gamma}{\Delta G_{V}-\frac{\gamma_{t}}{h}}=\frac{\gamma}{\left(\frac{k T}{\Omega} \ln \left[\frac{J \sqrt{2 \pi m k T}}{P_{s}}\right]-\frac{\gamma_{t}}{h}\right)} \\
& r_{\text {inclined }}^{*}=\frac{\gamma+\frac{\lambda \gamma_{t}}{\pi \sin \theta}}{\Delta G_{V}-\frac{f \gamma_{I T B}}{h}}=\frac{\gamma+\frac{\lambda \gamma_{t}}{\pi \sin \theta}}{\left(\frac{k T}{\Omega} \ln \left[\frac{J \sqrt{2 \pi m k T}}{P_{S}}\right]-\frac{f \gamma_{I T B}}{h}\right)}
\end{aligned}
$$

Where $\mathrm{k}$ is the Boltzmann constant, $\Omega$ is the atomic volume and $\mathrm{T}$ is the substrate temperature, $\mathrm{J}$ is the deposition flux, $\mathrm{m}$ is the atomic mass of the deposited metal, $\mathrm{P}_{\mathrm{S}}$ is the vapor pressure above solid. 
The critical radius difference between the twin nucleus and the perfect nucleus can be used to gauge the possibility of forming different types of twins. The critical radius difference between the parallel (or inclined) twin nucleus and the 'perfect' nucleus is expressed as $\Delta \gamma_{p p}^{*}=$ $\gamma_{\text {para }}^{*}-\gamma_{\text {perfect }}^{*}$ or $\Delta \gamma_{i p}^{*}=\gamma_{\text {inclined }}^{*}-\gamma_{\text {perfect }}^{*}$. The area fraction of the ITB in the inclined twin is an important variable that directly impacts the probability of nucleation of an inclined twin. By using $f=25 \%, 12 \%, 6 \%$, we can compare the probability of nucleation of an inclined twin with that of a parallel twin. The following values were used in the calculation: $\gamma=1.3 \mathrm{~J} / \mathrm{m}^{2}, \mathrm{~K}=1.38$ $\times 10^{-23} \mathrm{~J} / \mathrm{K}, \mathrm{T}=300 \mathrm{~K}, \gamma_{t}=0.075 \mathrm{~J} / \mathrm{m}^{2}$ and $\gamma_{\text {ITB }}=0.3 \mathrm{~J} / \mathrm{m}^{2}, \mathrm{~h}=2.33 \times 10^{-10} \mathrm{~m}, \mathrm{P}_{\mathrm{s}}=1.07 \times 10^{-5} \mathrm{~Pa}$, and $\Omega=1.66 \times 10^{-29} \mathrm{~m}^{3} /$ atom. $\mathrm{J}$ is deposition flux in units of monolayers deposited per second. Amonolayer of $\mathrm{Al}$ has an atomic area density of $1.41 \times 10^{19}$ atom/ $\mathrm{m}^{2}$ and the deposition rate in our experiments is $0.705 \mathrm{~nm} / \mathrm{s}$, thus $\mathrm{J}$ is estimated as $\sim 4.2 \times 10^{19}$ atom $/ \mathrm{m}^{2} \mathrm{~s}$.

As shown in Fig 7, for the Al film with parallel twins, the value of $\Delta \gamma_{p p}^{*} / r p$ is more than $22 \%$ even if the deposition rate is $10 \mathrm{~nm} / \mathrm{s}$, implying that it is difficult to form parallel twins. When $f=25 \%, \Delta \gamma_{i p}^{*} / r p$ is nearly the same as that of $\Delta \gamma_{p p}^{*} / r p$. However, a continuous decrease in $f$ value can significantly reduce $\Delta \gamma_{i p}^{*} / r p$. When $f=6 \%, \Delta \gamma_{i p}^{*} / r p$ drops to below $10 \%$ (the horizontal dash line in Fig. 7) at a deposition rate of $0.6 \mathrm{~nm} / \mathrm{s}$, implying the possibility to form inclined twins may have increased significantly at the current deposition conditions, $0.7 \mathrm{~nm} / \mathrm{s}$. This revised thermodynamic model suggests that the probability for the formation of an inclined growth twin could be much greater than that of a parallel twin, consistent with the observation of predominantly inclined growth twins in polycrystalline Al with high SFE.

\section{Promoting the formation of growth twins during the growth of films}


Beside the twin embryo formed during the nucleation stage, the twin formation process in Al may also be closely related to the continuous growth of the films. Fig. $5 \mathrm{~b}$ shows that the formation of an inclined CTB originated from the columnar grain boundary in $\mathrm{Al}$ film. The SAD pattern in Fig.5d indicates the formation of the inclined growth twin.

As shown in Fig. 8a, nuclei with different orientations formed randomly on substrate. Some of the nuclei may contain twins (Fig. 8a) and occasionally certain adjacent nuclei may happen to have the twinned orientation as evidenced in XTEM studies in Fig. 5e. During island coalescence, larger islands with low surface and interface energy may consume smaller or unfavorably orientated islands driven by the decrease in interface and surface energy (Fig. 8b). Meanwhile as shown in Fig. 8c, the high angle grain boundaries between the grain 1 and 2, and 1 and 4 , could be replaced by a CTB between the grain 1 and 4 as the CTB has much lower energy than a high angle grain boundary, leading to the formation of CTBs during the subsequent growth of the film.

\section{The increase of the fraction of the twinned grains with film thickness (when $h \leq 80 \mathrm{~nm}$ )}

As shown in Fig. 4, the fraction of the twinned grains rises monotonically to $\sim 9.5 \%$ when the film thickness increases to $80 \mathrm{~nm}$ and decreases afterwards. The fraction of the twinned grains is defined as the number of twinned grains per unit area $\left(\mathrm{P}_{\text {twin }}\right)$ divided by the total number of grains per unit area $\left(\mathrm{P}_{\text {grain }}\right)$. So mathematically it appears that either an increase in $\mathrm{P}_{\text {twin }}$ or a decrease in $\mathrm{P}_{\text {grain }}$ will result in a greater fraction of the twinned grains.

However our studies in Fig. 9 shows that both $\mathrm{P}_{\text {twin }}$ and $\mathrm{P}_{\text {grain }}$ decrease continuously with increasing film thickness. For instance, the $\mathrm{P}_{\text {twin }}$ decreases from 46 to 18 , and then to 7 twinned grains $/ \mu \mathrm{m}^{2}$ when $\mathrm{h}=20,40$ and $80 \mathrm{~nm}$, respectively. In parallel, the value of $\mathrm{P}_{\text {grain }}$ decreases at a greater rate, from 861 to 261 and then to 84 grains $/ \mu \mathrm{m}^{2}$ when $\mathrm{h}=20,40$ and $80 \mathrm{~nm}$, respectively. 
The reduction in the number of grains in thicker films arises from the island coalescence process [62]. When the island coalesced, the twins were terminated at the same time. However, as CTBs typically have lower energy than high angle grain boundaries, they are more stable and may have greater probability to survive during the island coalescence process. Furthermore new TBs may form during impingement of islands as evidenced in Fig. 5c and illustrated in Fig. 8c. Consequently the fraction of twinned grains increases with increasing film thickness when $\mathrm{h}$ is $80 \mathrm{~nm}$ or less.

The decrease of twinned grain fraction during continuous growth of the films (when $h>80$ nm)

When $\mathrm{h}>80 \mathrm{~nm}$, the fraction of the twinned grains decreases as shown in Fig. 4. A notable phenomenon in this regime is that the average grain size approaches a plateau $\sim 140 \mathrm{~nm}$ (or $\mathrm{P}_{\text {grain }}$ becomes a constant), because the films have entered the regime of a continuous growth of the columnar grains instead of islands coalescence. Correspondingly, the decrease of the fraction of the twinned grains results from the reduction of $\mathrm{P}_{\text {twin. }}$.

To explain the termination of twins during continuous growth of films when grain size saturates, we need to consider the energetics for the growth of CTB and ITB for the inclined twins. As shown schematically in Fig.10, the length of CTBs for inclined twins is proportional to the film thickness and hence the continuous growth of the CTBs with increasing film thickness will increase the total energy of the system. As the inclined CTBs extends to the film surface, there is no ITBs (or there is no extra energy necessary to create ITBs). It is important to realize that the termination of CTBs inside the films imply the necessity to form ITBs within the films. In Fig. 10a, there are two inclined twins (thin vs. thick) inside the film (h> $80 \mathrm{~nm}$ ) during the early growth stage. As shown in Fig. 10b, if the total energy of the CTBs $\left(\mathrm{W}_{\text {Ств}}\right)$ of the thin twin 
exceeds the formation energy of the ITB ( $\left.\mathrm{W}_{\text {ITB }}\right)$, the possibility to form an ITB will increase and the formation of the ITB terminates the continuous growth of the CTBs. Consequently the number of twinned grains (examined from plan-view TEM) will decrease. But the thick twin may continue its growth with the increase of film thickness because the energy $\mathrm{W}_{\mathrm{ITB}} \geqslant \mathrm{W}_{\mathrm{CTB}}$, or it is much more energetically costly to terminate a thick twin inside the film. The thick twin is eventually terminated when $\mathrm{W}_{\text {Ств }} \geqslant \mathrm{W}_{\text {Iтв }}($ Fig. 10c).

Foregoing discussions suggest that the growth of twins in thicker films could be affected by the energy minimization considering the energy difference between $\mathrm{W}_{\text {Iтв }}$ and $\mathrm{W}_{\text {Ств}}$. $\mathrm{W}_{\text {Iтв }}$ can be approximated as $\alpha \mathrm{T}_{\text {twin }} \mathrm{E}_{\mathrm{ITB}}$, where $\alpha$ is a constant related to the inclined twin angle and $\mathrm{E}_{\mathrm{ITB}}$ is the formation energy of an ITB per unit area. Similarly, $\mathrm{W}_{\mathrm{CTB}}=\mathrm{bhE}_{\mathrm{CTB}}$, where $\mathrm{b}$ is a constant which related to the inclined twin angle and $\mathrm{E}_{\mathrm{CTB}}$ is the energy of the CTB per unit area. $\alpha, b$, $\mathrm{E}_{\text {Iтв }}$ and $\mathrm{E}_{\mathrm{CTB}}$ are constants independent of film thickness. When $\mathrm{W}_{\mathrm{CTB}}=\mathrm{W}_{\text {IтB }}$, an inclined dashdot line is obtained as shown in Fig. 11. As discussed previously, the energy discrepancy between the ITB and CTB suggests the possibility to form an ITB. When $\mathrm{W}_{\mathrm{ITB}}>\mathrm{W}_{\mathrm{CTB}}$ (to the left side of the straight line), it is energetically feasible to extend the inclined growth twins during the growth of films. Whereas when $\mathrm{W}_{\mathrm{ITB}}<\mathrm{W}_{\mathrm{CTB}}$ (to the right side of the straight line), the continuous growth of the CTBs becomes energetically unfavorable. Consequently, the growth of a CTB will be terminated, leading to a reduction of the fraction of the twinned grains.

The reduction of the fraction of the twinned grains may also be related to the lack of continuous grain growth (or a lack of island coalescence). As mentioned earlier twins may nucleate during island coalescence, and thus the lack of island coalescence may reduce the probability to form growth twins. The current study on the formation of growth twins in 
polycrystalline $\mathrm{Al}$ is an important forward step towards the eventual goal - the synthesis of high density nanotwins in $\mathrm{Al}$ without buffer layers. There are numerous questions that remain to be examined in future studies, including the peculiar constant ratio between the average twin thickness and average grain size observed in this study.

\section{Conclusions}

Sputter-deposited polycrystalline Al films contain growth twins and the fraction of twinned grain increased with increasing film thickness to a maximum value, $\sim 9.5 \%$, when $\mathrm{h}=$ $80 \mathrm{~nm}$, and decreased thereafter in the thicker films. An inclined twin nucleation model has been provided from the thermodynamics perspective to explain the formation mechanism of the growth twins in Al films. The termination mechanism for the growth of the inclined twins in thicker films may be related to the competition between the energy of CTB and ITB, the elimination of fine nanotwins, and the lack of grain growth via island coalescence. Although the fraction of twinned grains remains low, the twin formation mechanisms presented in this study suggest new perspectives to tailor the formation of grow twins in high SFE metals, such as Al.

\section{Acknowledgement}

XZ acknowledges financial support by DoE-OBES under grant no. DE-SC0010482. HW acknowledges the support from the Office of Naval Research (under Dr. Lawrence Kabacoff and and Dr. Antti Makinen N000141310555). ZF is supported by NSF-CMMI under grant No. 1161978. Access to the DOE-Center for Integrated Nanotechnologies (CINT) at Los Alamos and 
Sandia National Laboratories and_the microscopes at the Microscopy and Imaging Center at Texas A\&M University are also acknowledged.

\section{References}

[1] O. Anderoglu, A. Misra, H. Wang, F. Ronning, M.F. Hundley, X. Zhang. Epitaxial nanotwinned Cu films with high strength and high conductivity, Appl Phys Lett 93 (2008) 083108.

[2] L. Lu, Y. Shen, X. Chen, L. Qian, K. Lu. Ultrahigh strength and high electrical conductivity in copper, Science 304 (2004) 422-426.

[3] X. Zhang, A. Misra. Superior thermal stability of coherent twin boundaries in nanotwinned metals, Scripta Materialia 66 (2012) 860-865.

[4] D. Bufford, H. Wang, X. Zhang. High strength, epitaxial nanotwinned Ag films, Acta Materialia 59 (2011) 93-101.

[5] Y. Zhao, T.A. Furnish, M.E. Kassner, A.M. Hodge. Thermal stability of highly nanotwinned copper: The role of grain boundaries and texture, Journal of Materials Research 27 (2012) 3049-3057.

[6] T. LaGrange, B.W. Reed, M. Wall, J. Mason, T. Barbee, M. Kumar. Topological view of the thermal stability of nanotwinned copper, Appl Phys Lett 102 (2013) 011905.

[7] O. Anderoglu, A. Misra, H. Wang, X. Zhang. Thermal stability of sputtered Cu films with nanoscale growth twins, Journal of Applied Physics 103 (2008) 094322.

[8] J. Brown, N. Ghoniem. Structure and motion of junctions between coherent and incoherent twin boundaries in copper, Acta Materialia 57 (2009) 4454-4462.

[9] D. Bufford, H. Wang, X. Zhang. Thermal stability of twins and strengthening mechanisms in differently oriented epitaxial nanotwinned Ag films, Journal of Materials Research 28 (2013) 1729-1739. [10] L. Lu, X. Chen, X. Huang, K. Lu. Revealing the maximum strength in nanotwinned copper, Science 323 (2009) 607-610.

[11] X. Zhang, H. Wang, X. Chen, L. Lu, K. Lu, R. Hoagland, A. Misra. High-strength sputterdeposited $\mathrm{Cu}$ foils with preferred orientation of nanoscale growth twins, Appl Phys Lett 88 (2006) 173116-173116-173113.

[12] Z.-H. Jin, P. Gumbsch, E. Ma, K. Albe, K. Lu, H. Hahn, H. Gleiter. The interaction mechanism of screw dislocations with coherent twin boundaries in different face-centred cubic metals, Scripta Materialia 54 (2006) 1163-1168. 
[13] C. Deng, F. Sansoz. Enabling ultrahigh plastic flow and work hardening in twinned gold nanowires, Nano letters 9 (2009) 1517-1522.

[14] X. Li, Y. Wei, L. Lu, K. Lu, H. Gao. Dislocation nucleation governed softening and maximum strength in nano-twinned metals, Nature 464 (2010) 877-880.

[15] J. Wang, N. Li, O. Anderoglu, X. Zhang, A. Misra, J. Huang, J. Hirth. Detwinning mechanisms for growth twins in face-centered cubic metals, Acta Materialia 58 (2010) 2262-2270.

[16] A. Hodge, T. Furnish, C. Shute, Y. Liao, X. Huang, C. Hong, Y. Zhu, T. Barbee Jr, J. Weertman. Twin stability in highly nanotwinned $\mathrm{Cu}$ under compression, torsion and tension, Scripta Materialia 66 (2012) 872-877.

[17] Z. Wu, Y. Zhang, D. Srolovitz. Deformation mechanisms, length scales and optimizing the mechanical properties of nanotwinned metals, Acta Materialia 59 (2011) 6890-6900.

[18] T. Zhu, H. Gao. Plastic deformation mechanism in nanotwinned metals: an insight from molecular dynamics and mechanistic modeling, Scripta Materialia 66 (2012) 843-848.

[19] Y.M. Wang, F. Sansoz, T. LaGrange, R.T. Ott, J. Marian, T.W. Barbee Jr, A.V. Hamza. Defective twin boundaries in nanotwinned metals, Nature materials 12 (2013) 697-702.

[20] N. Li, J. Wang, A. Misra, X. Zhang, J. Huang, J. Hirth. Twinning dislocation multiplication at a coherent twin boundary, Acta Materialia 59 (2011) 5989-5996.

[21] Z.-H. Jin, P. Gumbsch, K. Albe, E. Ma, K. Lu, H. Gleiter, H. Hahn. Interactions between nonscrew lattice dislocations and coherent twin boundaries in face-centered cubic metals, Acta Materialia 56 (2008) 1126-1135.

[22] J. Wang, A. Misra, J. Hirth. Shear response of $\Sigma 3\{112\}$ twin boundaries in face-centered-cubic metals, Physical Review B 83 (2011) 064106.

[23] N. Li, J. Wang, J. Huang, A. Misra, X. Zhang. Influence of slip transmission on the migration of incoherent twin boundaries in epitaxial nanotwinned Cu, Scripta Materialia 64 (2011) 149-152.

[24] D. Bufford, Y. Liu, J. Wang, H. Wang, X. Zhang. In situ nanoindentation study on plasticity and work hardening in aluminium with incoherent twin boundaries, Nature communications 5 (2014).

[25] X. Zhang, A. Misra, H. Wang, M. Nastasi, J. Embury, T. Mitchell, R. Hoagland, J. Hirth. Nanoscale-twinning-induced strengthening in austenitic stainless steel thin films, Appl Phys Lett 84 (2004) 1096-1098.

[26] X. Zhang, A. Misra, H. Wang, A. Lima, M. Hundley, R. Hoagland. Effects of deposition parameters on residual stresses, hardness and electrical resistivity of nanoscale twinned 330 stainless steel thin films, Journal of applied physics 97 (2005) 094302.

[27] Y. Liu, J. Jian, Y. Chen, H. Wang, X. Zhang. Plasticity and ultra-low stress induced twin boundary migration in nanotwinned $\mathrm{Cu}$ by in situ nanoindentation studies, Appl Phys Lett 104 (2014) 231910.

[28] N. Li, J. Wang, X. Zhang, A. Misra. In-situ TEM study of dislocation-twin boundaries interaction in nanotwinned $\mathrm{Cu}$ films, JOM 63 (2011) 62-66.

[29] X. Chen, L. Lu. Work hardening of ultrafine-grained copper with nanoscale twins, Scripta materialia 57 (2007) 133-136.

[30] O. Anderoglu, A. Misra, J. Wang, R. Hoagland, J. Hirth, X. Zhang. Plastic flow stability of nanotwinned $\mathrm{Cu}$ foils, International Journal of Plasticity 26 (2010) 875-886.

[31] C. Shute, B. Myers, S. Xie, T. Barbee, A. Hodge, J. Weertman. Microstructural stability during cyclic loading of multilayer copper/copper samples with nanoscale twinning, Scripta Materialia 60 (2009) 1073-1077.

[32] C. Shute, B. Myers, S. Xie, S.-Y. Li, T. Barbee, A. Hodge, J. Weertman. Detwinning, damage and crack initiation during cyclic loading of $\mathrm{Cu}$ samples containing aligned nanotwins, Acta Materialia 59 (2011) 4569-4577.

[33] A. Hodge, T. Furnish, A. Navid, T. Barbee. Shear band formation and ductility in nanotwinned $\mathrm{Cu}$, Scripta Materialia 65 (2011) 1006-1009.

[34] V. Narayanan, S. Mahajan, K.J. Bachmann, V. Woods, N. Dietz. Stacking faults and twins in gallium phosphide layers grown on silicon, Philosophical Magazine A 82 (2002) 685-698. 
[35] X. Zhang, A. Misra, H. Wang, T. Shen, M. Nastasi, T. Mitchell, J. Hirth, R. Hoagland, J. Embury. Enhanced hardening in $\mathrm{Cu} / 330$ stainless steel multilayers by nanoscale twinning, Acta Materialia 52 (2004) 995-1002.

[36] Q. Xue, X. Liao, Y. Zhu, G. Gray. Formation mechanisms of nanostructures in stainless steel during high-strain-rate severe plastic deformation, Materials Science and Engineering: A 410 (2005) 252256.

[37] K.-C. Chen, W.-W. Wu, C.-N. Liao, L.-J. Chen, K. Tu. Observation of atomic diffusion at twinmodified grain boundaries in copper, Science 321 (2008) 1066-1069.

[38] L. Liu, J. Wang, S. Gong, S. Mao. High resolution transmission electron microscope observation of zero-strain deformation twinning mechanisms in Ag, Physical review letters 106 (2011) 175504.

[39] D. Jang, C. Cai, J.R. Greer. Influence of homogeneous interfaces on the strength of $500 \mathrm{~nm}$ diameter $\mathrm{Cu}$ nanopillars, Nano letters 11 (2011) 1743-1746.

[40] K. Lu, F. Yan, H. Wang, N. Tao. Strengthening austenitic steels by using nanotwinned austenitic grains, Scripta Materialia 66 (2012) 878-883.

[41] H.-Y. Hsiao, C.-M. Liu, H.-w. Lin, T.-C. Liu, C.-L. Lu, Y.-S. Huang, C. Chen, K. Tu. Unidirectional growth of microbumps on (111)-oriented and nanotwinned copper, Science 336 (2012) 1007-1010.

[42] I.J. Beyerlein, X. Zhang, A. Misra. Growth twins and deformation twins in metals, Annual Review of Materials Research 44 (2014) 329-363.

[43] R. Ott, J. Geng, M. Besser, M. Kramer, Y. Wang, E. Park, R. LeSar, A. King. Optimization of strength and ductility in nanotwinned ultra-fine grained Ag: Twin density and grain orientations, Acta Materialia 96 (2015) 378-389.

[44] S. Mahajan, C.S. Pande, M.A. Imam, B.B. Rath. Formation of annealing twins in f.c.c. crystals, Acta Materialia 45 (1997) 2633-2638.

[45] Y. Zhu, X. Liao, X. Wu. Deformation twinning in nanocrystalline materials, Progress in Materials Science 57 (2012) 1-62.

[46] H. Van Swygenhoven, P. Derlet, A. Frøseth. Stacking fault energies and slip in nanocrystalline metals, Nature materials 3 (2004) 399-403.

[47] Y. Zhu, J. Narayan, J. Hirth, S. Mahajan, X. Wu, X. Liao. Formation of single and multiple deformation twins in nanocrystalline fcc metals, Acta Materialia 57 (2009) 3763-3770.

[48] S. Mahajan. Critique of mechanisms of formation of deformation, annealing and growth twins: face-centered cubic metals and alloys, Scripta Materialia 68 (2013) 95-99.

[49] V. Yamakov, D. Wolf, S.R. Phillpot, A.K. Mukherjee, H. Gleiter. Dislocation processes in the deformation of nanocrystalline aluminium by molecular-dynamics simulation, Nature materials 1 (2002) 45-49.

[50] M. Chen, E. Ma, K.J. Hemker, H. Sheng, Y. Wang, X. Cheng. Deformation twinning in nanocrystalline aluminum, Science 300 (2003) 1275-1277.

[51] X. Liao, F. Zhou, E. Lavernia, D. He, Y. Zhu. Deformation twins in nanocrystalline Al, Appl Phys Lett 83 (2003) 5062-5064.

[52] V. Yamakov, D. Wolf, S. Phillpot, A. Mukherjee, H. Gleiter. Deformation-mechanism map for nanocrystalline metals by molecular-dynamics simulation, nature materials 3 (2004) 43-47.

[53] Z. Budrovic, H. Van Swygenhoven, P.M. Derlet, S. Van Petegem, B. Schmitt. Plastic deformation with reversible peak broadening in nanocrystalline nickel, Science 304 (2004) 273-276.

[54] X.Z. Liao, Y.H. Zhao, S.G. Srinivasan, Y.T. Zhu, R.Z. Valiev, D.V. Gunderov. Deformation twinning in nanocrystalline copper at room temperature and low strain rate, Appl Phys Lett 84 (2004) 592-594.

[55] B. Li, B. Cao, K. Ramesh, E. Ma. A nucleation mechanism of deformation twins in pure aluminum, Acta Materialia 57 (2009) 4500-4507.

[56] S. Hai, E. Tadmor. Deformation twinning at aluminum crack tips, Acta Materialia 51 (2003) 117131. 
[57] D. Bufford, Z. Bi, Q. Jia, H. Wang, X. Zhang. Nanotwins and stacking faults in high-strength epitaxial Ag/Al multilayer films, Appl Phys Lett 101 (2012) 223112.

[58] D. Bufford, Y. Liu, Y. Zhu, Z. Bi, Q. Jia, H. Wang, X. Zhang. Formation mechanisms of highdensity growth twins in aluminum with high stacking-fault energy, Materials Research Letters 1 (2013) 51-60.

[59] X. Zhang, D. BUFFORD, H. Wang, Y. Liu. Method for producing high stacking fault energy (sfe) metal films, foils, and coatings with high-density nanoscale twin boundaries. Google Patents, 2014.

[60] K. Yu, D. Bufford, Y. Chen, Y. Liu, H. Wang, X. Zhang. Basic criteria for formation of growth twins in high stacking fault energy metals, Appl Phys Lett 103 (2013) 181903.

[61] X. Zhang, O. Anderoglu, A. Misra, H. Wang. Influence of deposition rate on the formation of growth twins in sputter-deposited 330 austenitic stainless steel films, Appl Phys Lett 90 (2007) 153101. [62] I. Petrov, P. Barna, L. Hultman, J. Greene. Microstructural evolution during film growth, Journal of Vacuum Science \& Technology A 21 (2003) S117-S128.

Figure captions

Figure 1. Transmission electron microscopy (TEM) micrographs of Al films with different film thickness showing the formation of growth twins. (a) $h=20 \mathrm{~nm}$, (b) $h=40 \mathrm{~nm}$, (c) $\mathrm{h}=60 \mathrm{~nm}$, (d) $\mathrm{h}=80 \mathrm{~nm}$, (e) $\mathrm{h}=100 \mathrm{~nm}$, (f) $\mathrm{h}=140 \mathrm{~nm}$. Twins were frequently observed as labeled selectively by arrows in the micrographs. The inserted selected area diffraction (SAD) patterns indicate the formation of polycrystalline Al films.

Figure 2. Microstructure of long coherent twin boundaries (CTBs) in twinned Al films. (a) Low magnification TEM micrograph of the CTB multi-junction in Al film, $h=40 \mathrm{~nm}$. (b) HRTEM micrograph showing the intersection of CTBs at the junctions. (c) The fast Fourier transform 
(FFT) of the CTB junctions confirmation the formation of two sets of twins. (d) HRTEM micrograph showing the CTB1 decorated with stacking faults.

Figure 3. Statistic distributions of grain size and twin thickness for Al films with various film thickness. (a) Statistical variation of grain size with different film thickness. The average grain size increases monotonically up to $\sim 138 \mathrm{~nm}$ with increasing film thickness to $100 \mathrm{~nm}$, and then reaches a plateau. (b) In parallel the average twin thickness increases to $\sim 52-56 \mathrm{~nm}$ when $\mathrm{h}=$ $100 \mathrm{~nm}$, and reaches a saturation.

Figure 4. The evolution of fraction of twinned grains, average twin thickness and average grain size with Al film thickness. The fraction of twinned grains increases continuously with increasing film thickness, reaches a maximum of $\sim 9 \%$ when $\mathrm{h}=80 \mathrm{~nm}$, and decreases thereafter in thicker films. The average twin thickness and grain sizes increase monotonically with film thickness and approach plateaus when $\mathrm{h}=100 \mathrm{~nm}$.

Figure 5. Microstructure of inclined twins in Al films on Si substrate. (a) Low magnification cross-section TEM micrograph of the twinned Al films, the inclined twin nucleated at the Si surface. (b) The SAD pattern of R1 in Fig. 5a. (c) Low magnification cross-section TEM 
micrograph of the twinned Al films, the inclined twin nucleated inside the Al films. (d) The SAD pattern of R2 in Fig. 5c. (f) the SAD pattern of R3 in Fig. 5e.

Figure 6. Schematic diagrams comparing the nucleation of (a) a perfect nucleus, (b) a parallel twinned nucleus and (c) a nucleus with inclined growth twin on Al matrix. (a) The perfect nucleus and the matrix has the same <111> crystal orientation. (b) The parallel twin nucleus forms (111) CTB on the (111) matrix. (c) A nucleus contains both inclined CTB and incoherent twin boundary (ITB) with the matrix. Note an example of (100) matrix is used to illustrate the concept without losing the generality of the model. A fraction of the matrix-nucleation interface contains ITB with an area of $\mathrm{A}_{\text {ITB }}$, whereas the remaining of the nucleus has the same crystal orientation as that of the matrix.

Figure 7. Plots of the percentage of critical radius difference between perfect nuclei and parallel twin nuclei $\Delta r_{\text {para }} / r_{p}$ (and between perfect and inclined twin nuclei $\Delta r_{\text {incl }} / r_{p}$, where $\Delta r_{\text {para }}=r_{\text {para }}-r_{p}$, $\Delta r_{\text {incl }}=r_{\text {incl }}-r_{p}$, and $r_{p}, r_{\text {para }}, r_{\text {incl }}$ represent the radius of perfect, parallel and inclined twin nuclei respectively. For parallel twins, $r_{\text {para }}$ is at least $25 \%$ greater than that of $r_{p}$ even at a very high deposition rate, implying the nucleation of parallel growth twins in Al is very difficult in comparison for inclined twins, by reducing the area fraction of $\mathrm{A}_{\text {Iтв }}$ to $12 \%$ (or less) of the contact area (between matrix and twin nuclei), $r_{\text {incl }}$ is merely $\sim 10 \%$ greater than that of $r_{p}$, implying the nucleation of inclined twins in $\mathrm{Al}$ is easier than the nucleation of parallel twins. 
Figure 8. Schematics illustrating different twin formation mechanisms. In the first case, inclined twins may nucleate directly on the matrix as shown in (b). In the second case, two grains, 1 and 4, with twin orientation may impinge upon each other as shown in (c) to form a twin boundary during the growth of films.

Figure 9. Plots of twinned grain density and grain density versus film thickness. Twinned grain density follows the tendency of grain density with the increase of film thickness. The density drops quickly before film thickness reach $60 \mathrm{~nm}$ and goes to plateaus gradually.

Figure 10. Schematics illustrating the termination of thin inclined twins and continuous growth of thick inclined twins in Al by using the energy balance concept. When the energy of CTBs is less than or equal to the formation energy of ITB, the inclined twins may grow continuously (a). In contrast, the growth of inclined twins become difficult when the opposite holds true. Thus, the growth of thinner twins terminates earlier than thicker twins (b-c). 


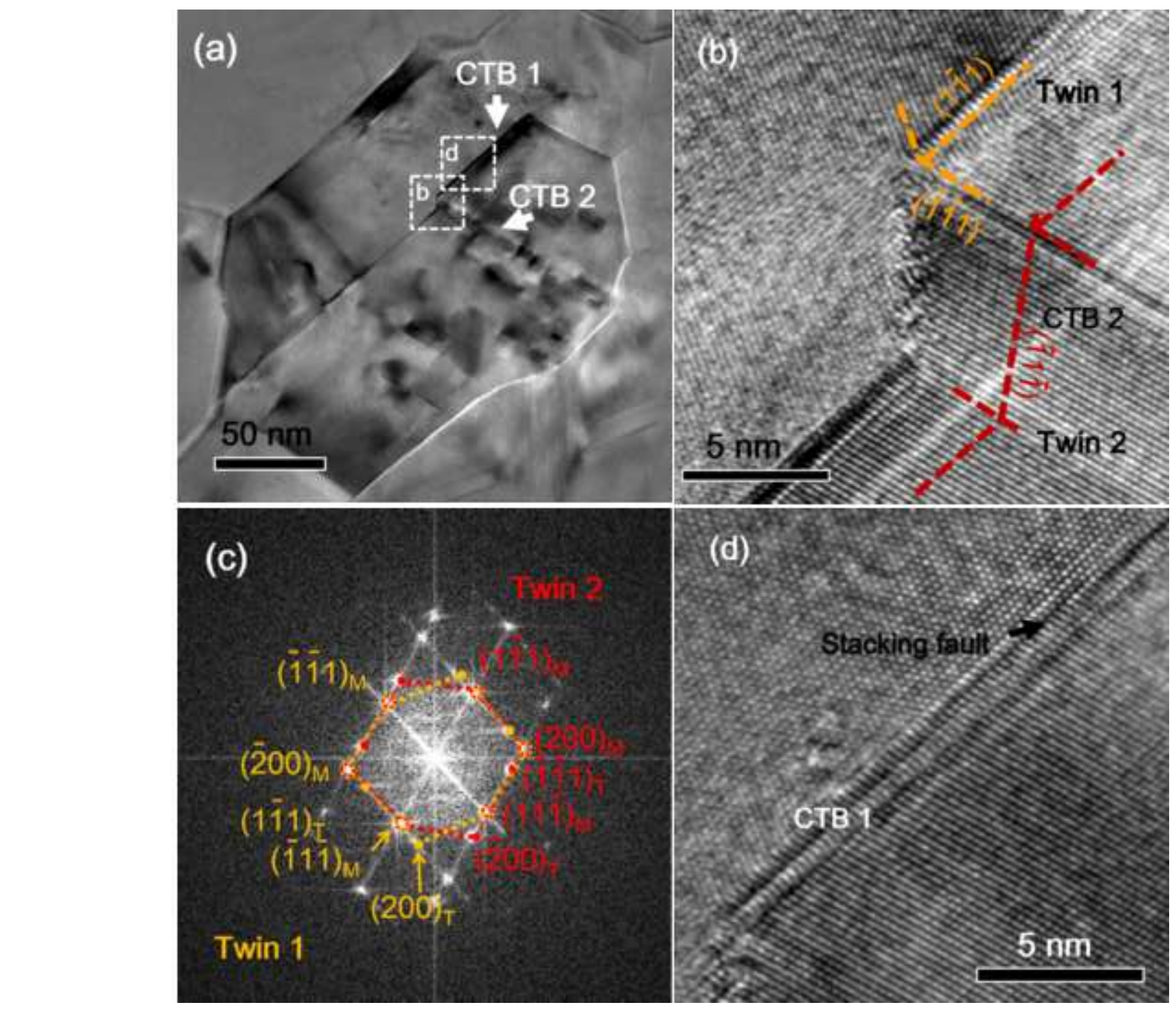

. 

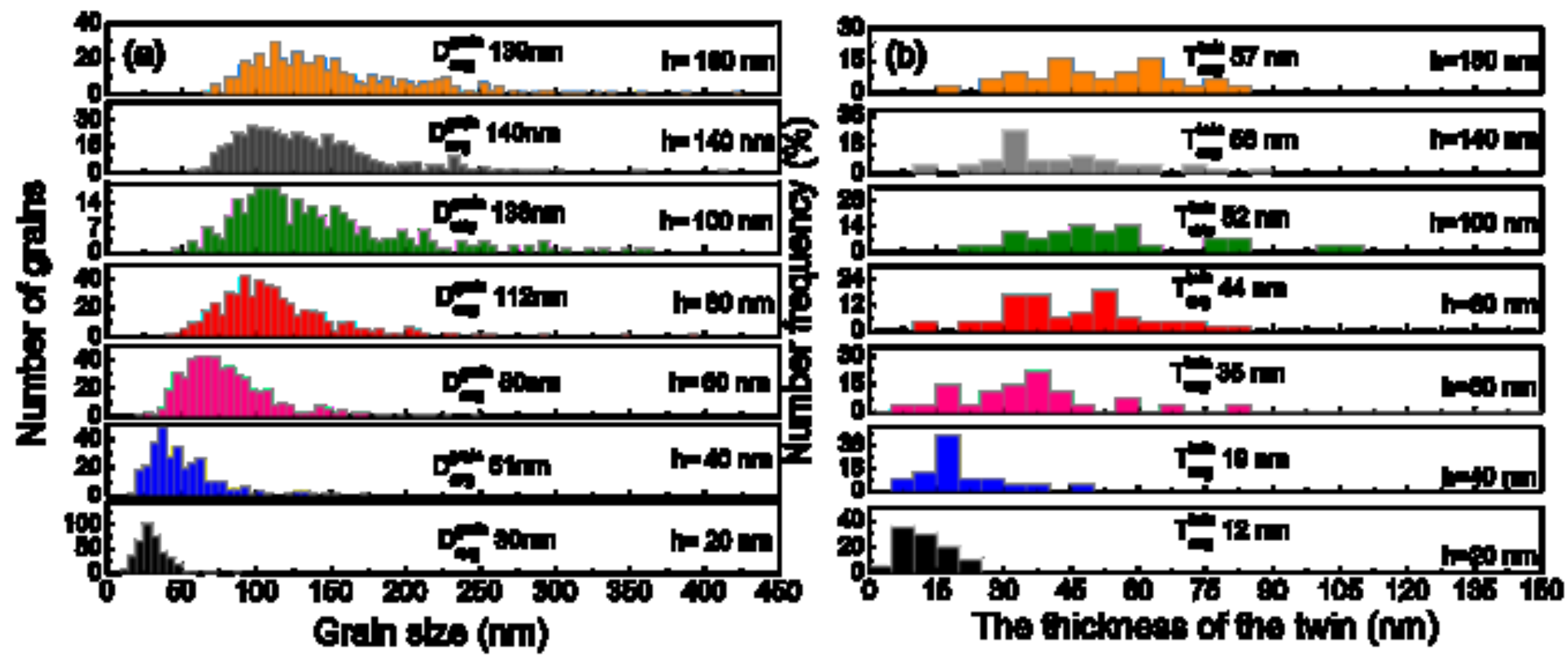


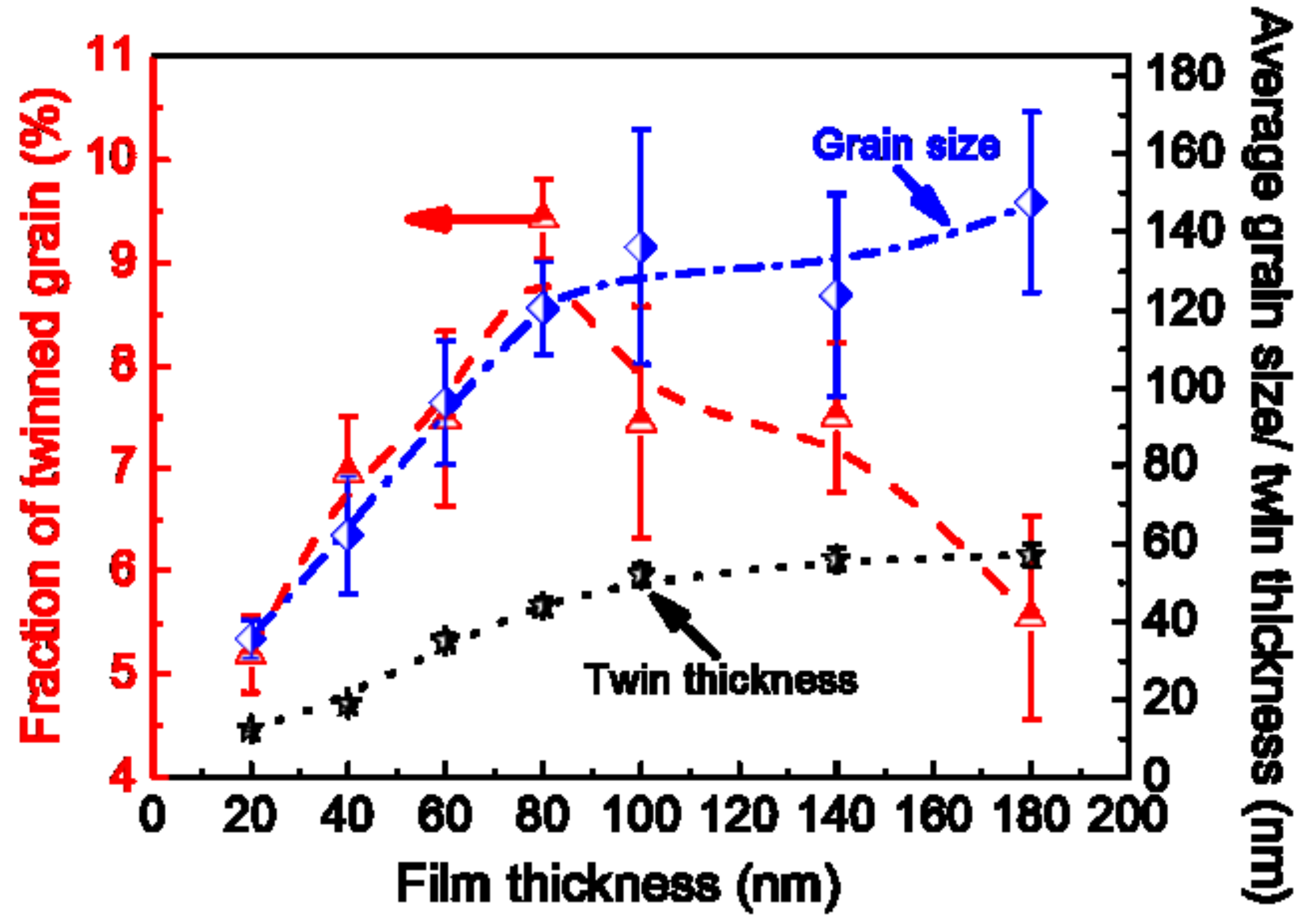




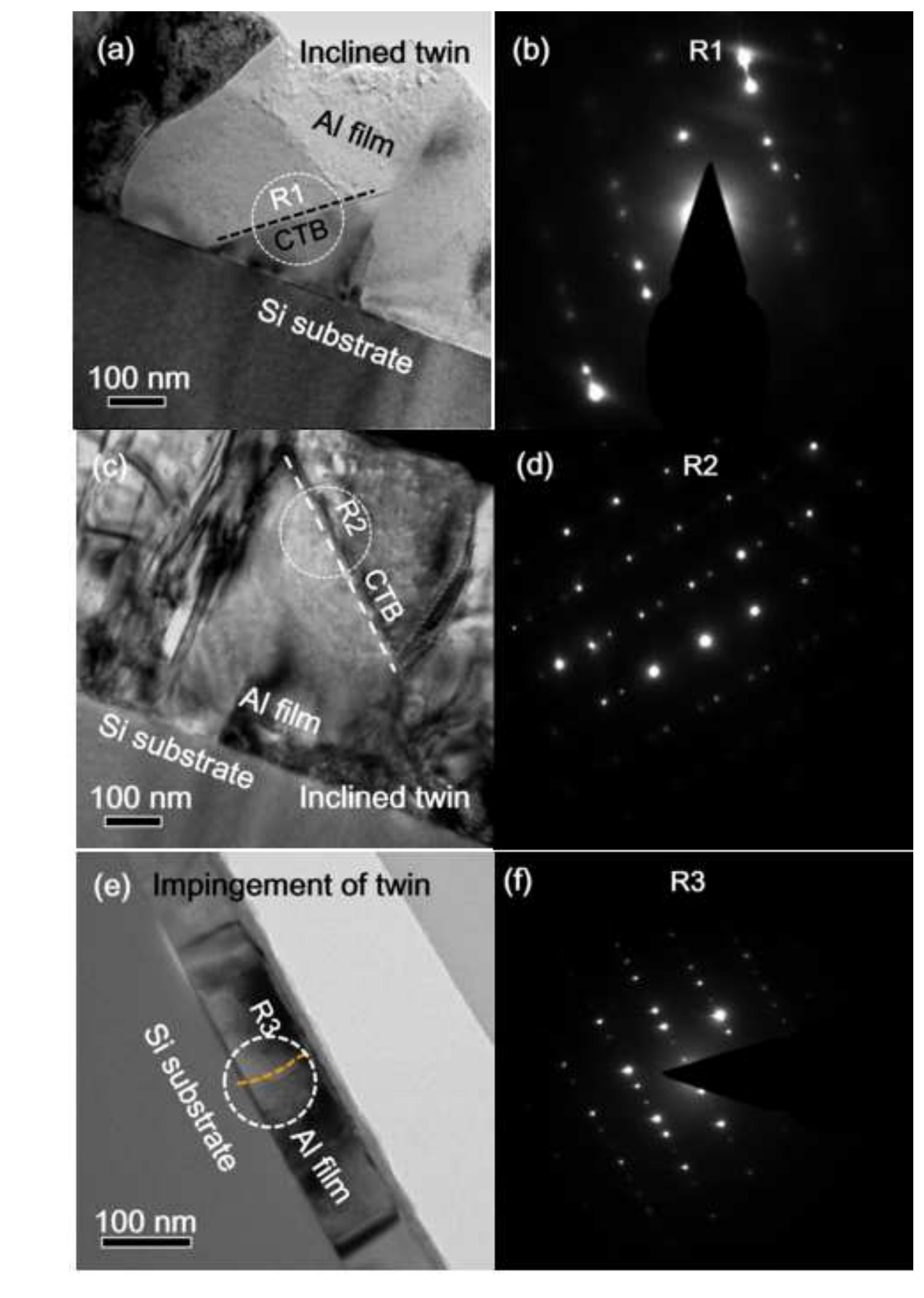

\section{Figure five}

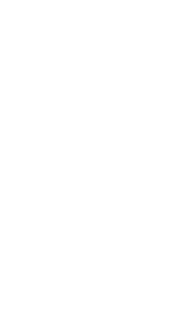

( 


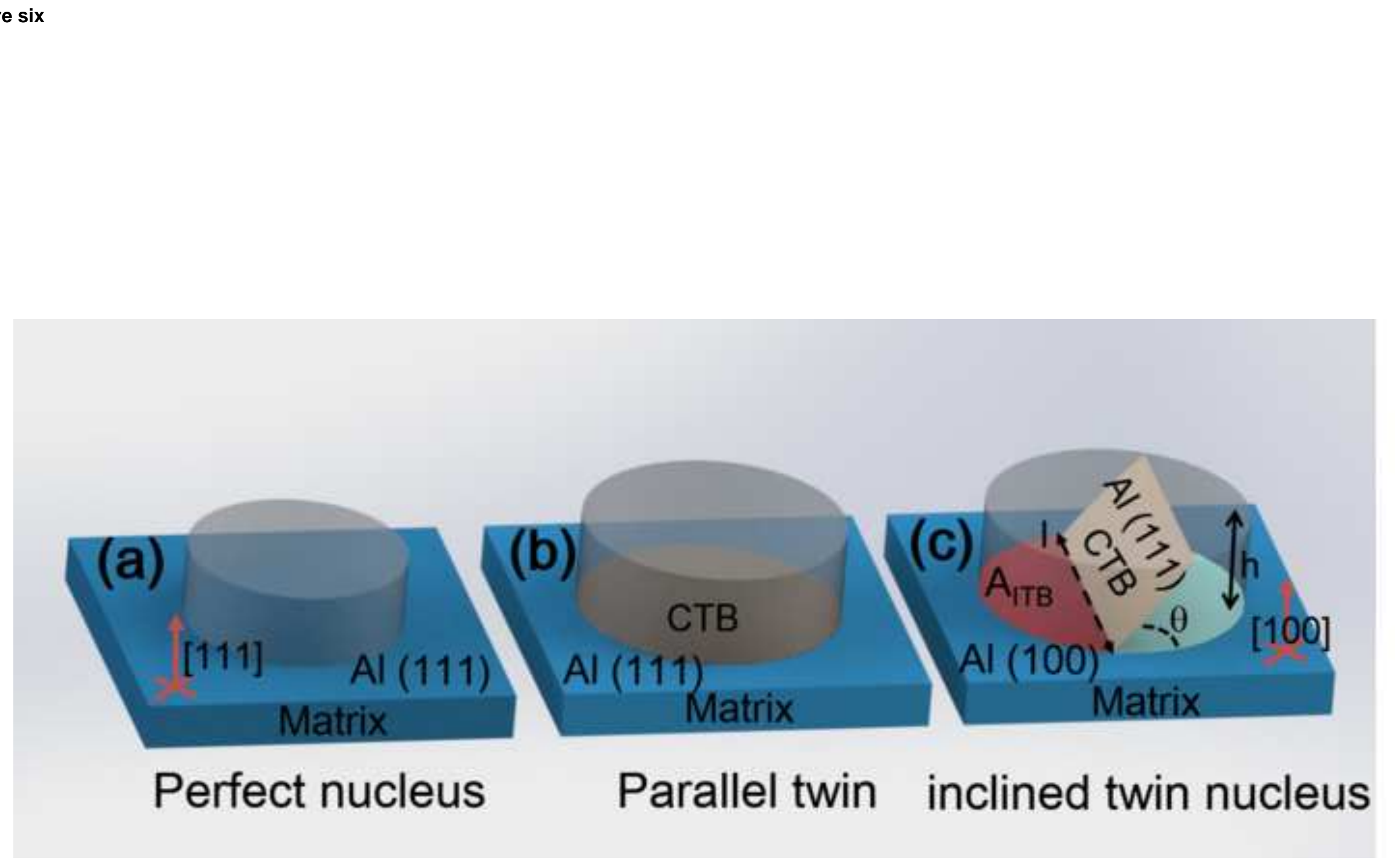

Perfect nucleus

\begin{abstract}
Matrix
\end{abstract}
Parallel twin inclined twin nucleus 


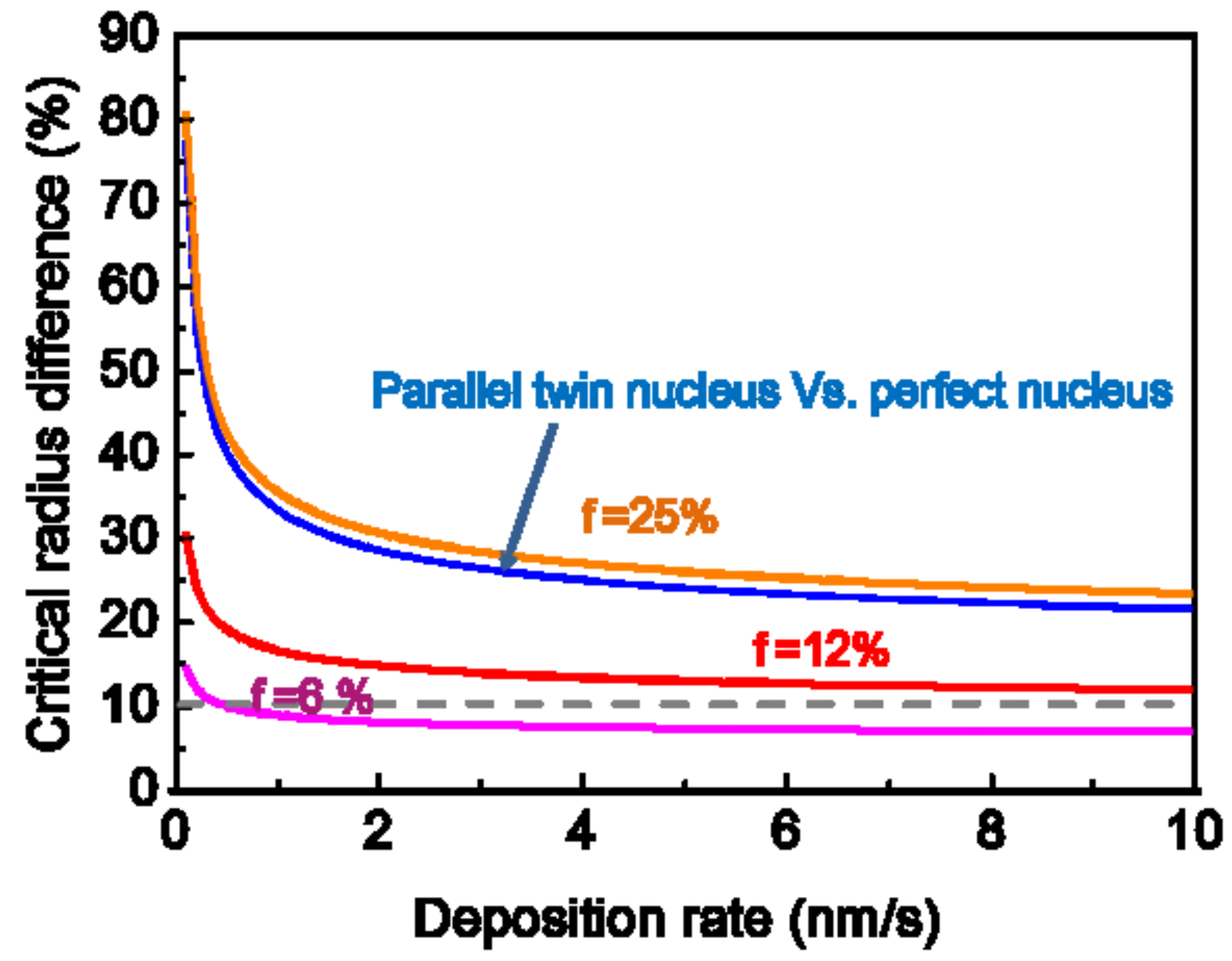




\section{Nucleation}

\section{Inclined twin} nucleus

anman

(a) Substrate

Growth + Nuclegtion

Twin 1

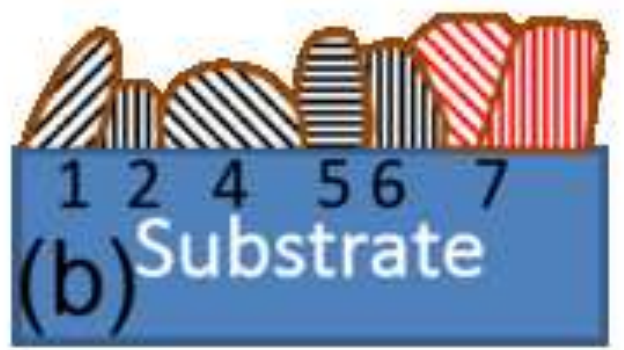

\section{Impingement of twin}

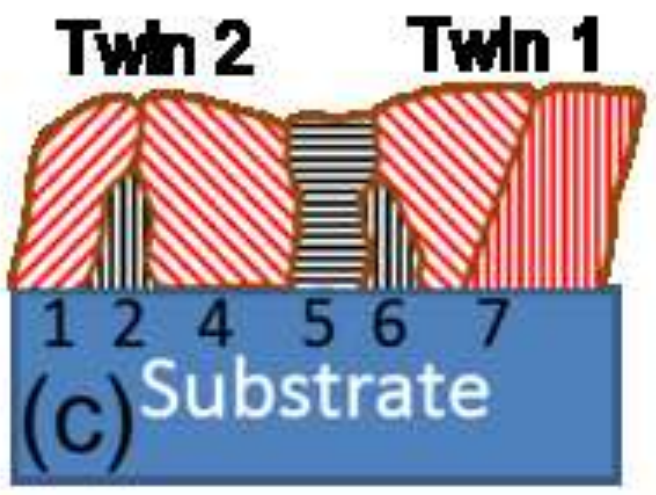




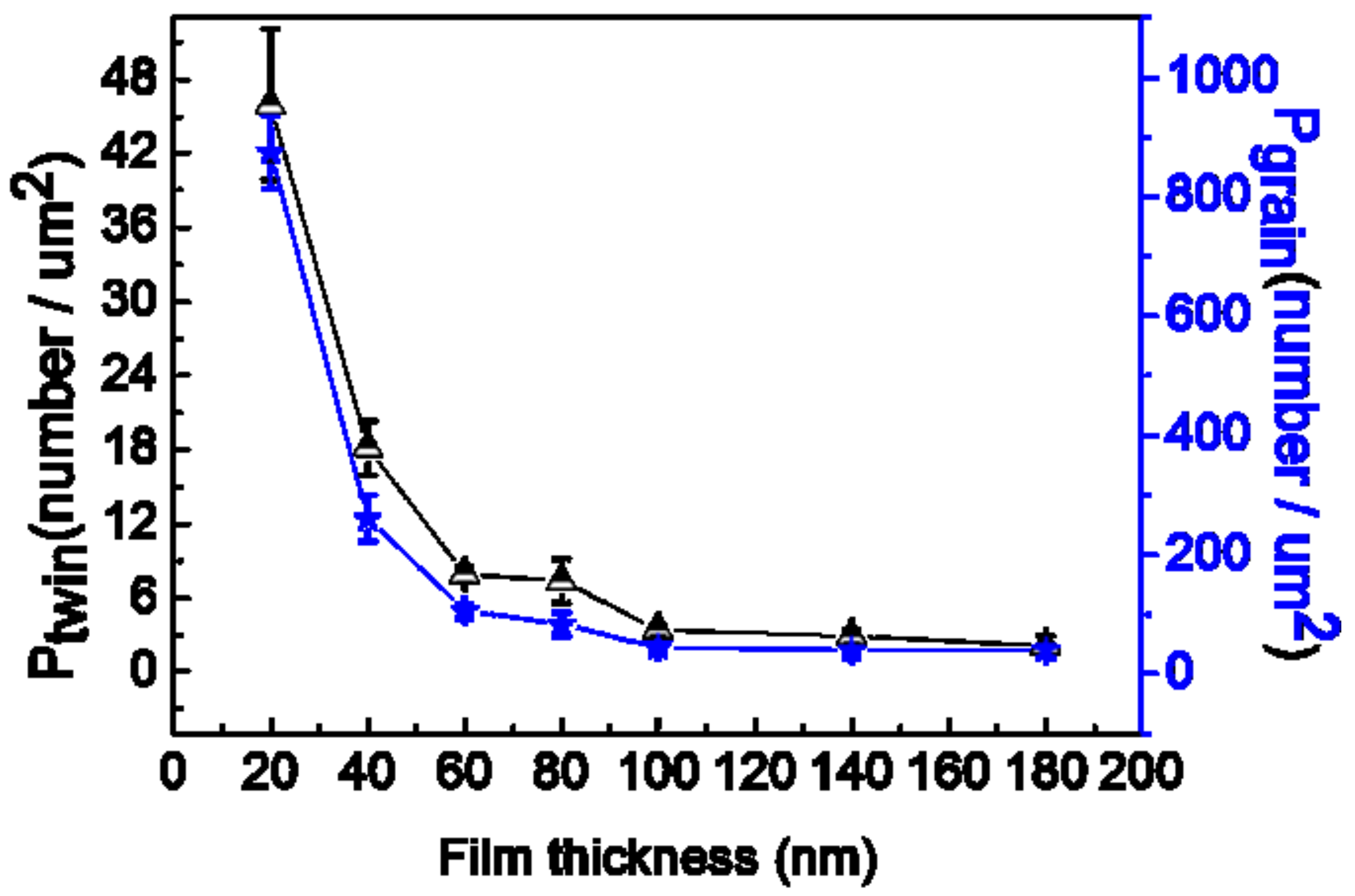


Thicker twin

Thinner twin $\begin{gathered}W_{\text {CTB }}>W_{\text {mB }} \\ \text { atable }\end{gathered}$

$W_{\text {CTR }}>W$
gtable

\section{Stable}

\section{$W_{\text {CTB }}>W_{\text {TB }}$}

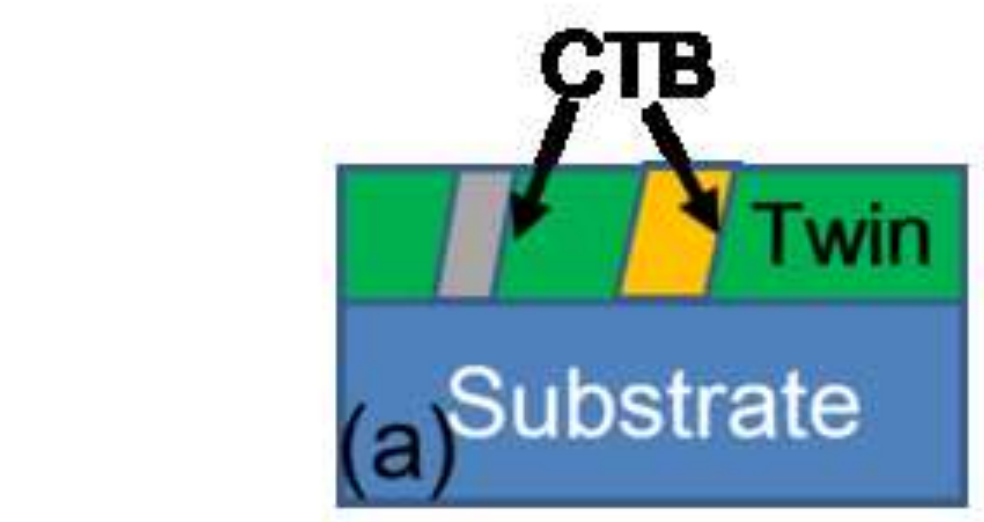

$W_{\text {CTE }}>W_{\text {ITB }}$ Stable

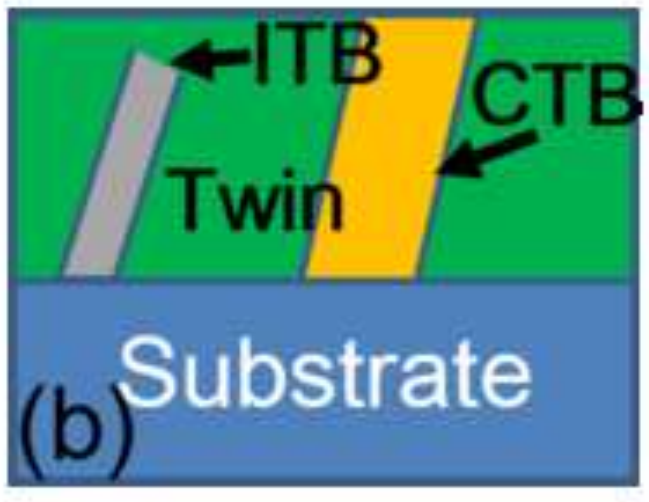

$W_{\text {CTB }}<W_{\text {ITB }}$

Unstable

\section{$W_{\mathrm{CTB}}<W_{\mathrm{IB}}$ unetable}

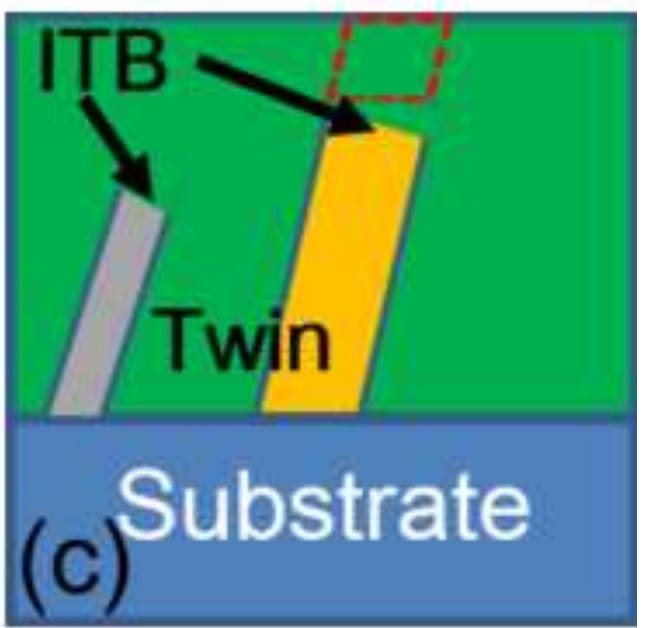




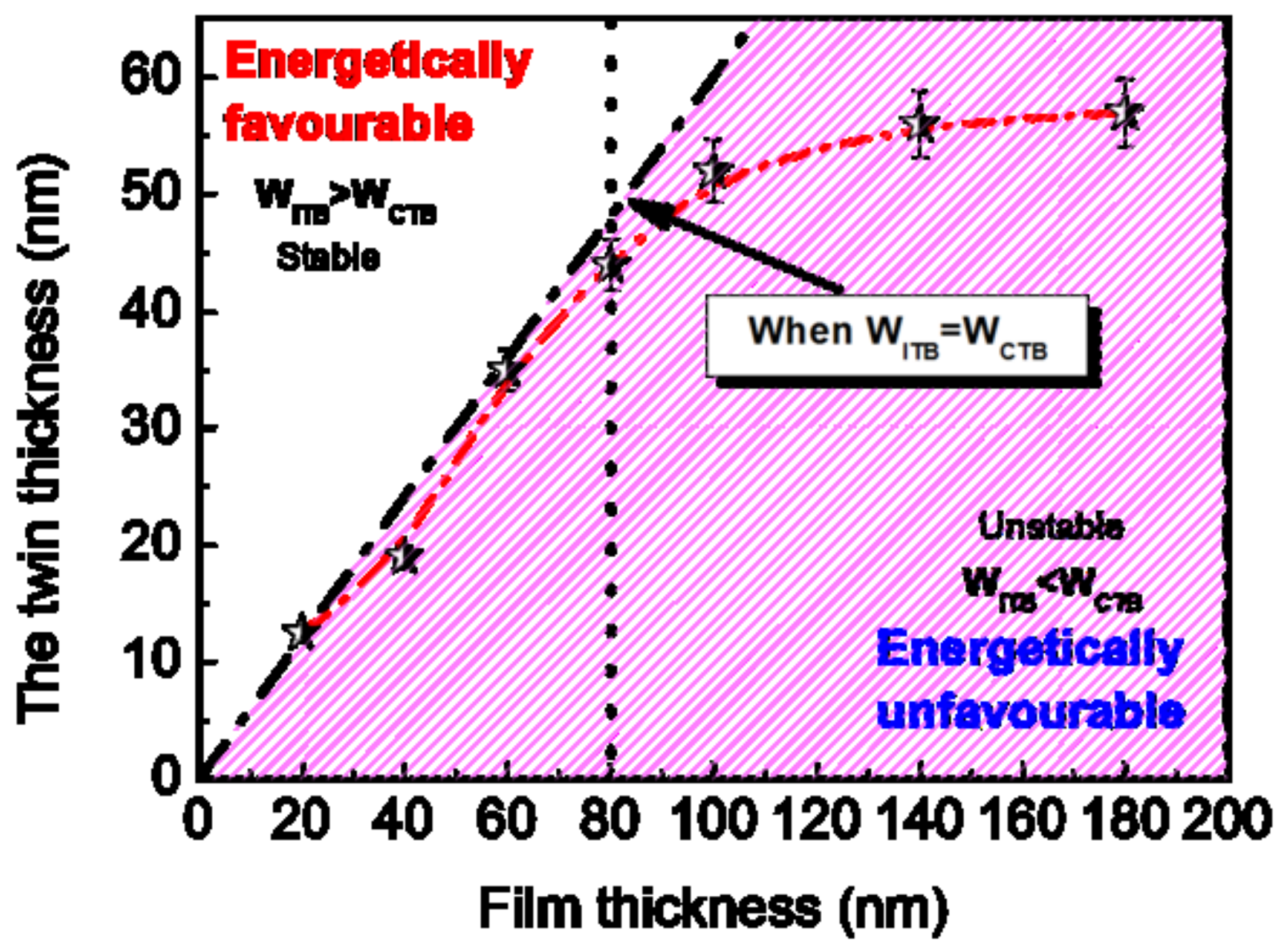



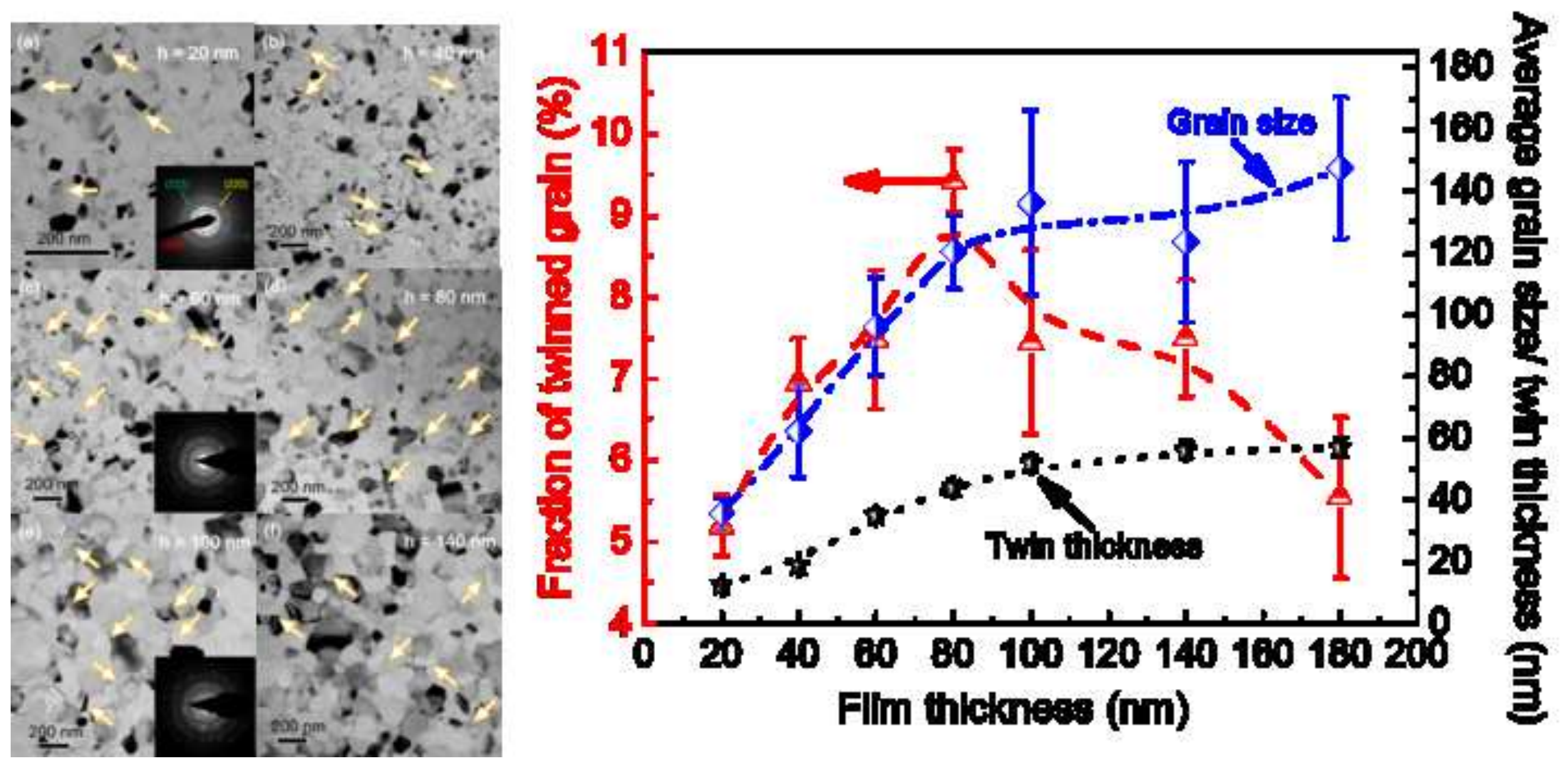